\title{
Multi-Objective Decision Analytics for Short-Notice Bushfire Evacuation: An Australian Case Study
}

\author{
Shahrooz Shahparvari \\ School of Business IT \& Logistics \\ RMIT University \\ shahrooz.shahparvari@rmit.edu.au
}

\author{
Prem Chhetri \\ School of Business IT \& Logistics \\ RMIT University
}

\author{
Ahmad Abareshi \\ School of Business IT \& Logistics \\ RMIT University \\ Babak Abbasi \\ School of Business IT \& Logistics \\ RMIT University
}

\section{Damminda Alahakoon \\ La Trobe Business School \\ La Trobe University}

\begin{abstract}
Late evacuation in a bushfire is a crucial stage of emergency response, which requires a quick response under life-threatening conditions. Lack of operational intelligence and decision support system to execute evacuation of residents within a 10 minutes time window were among key factors, which contributed to the loss of 119 lives (68 percent of total fatalities) during the Black Saturday 2009 bushfire in Victoria. Hard constraints of the limited time window, the uncertainty of bushfire spread, road disruptions and elderly and disabled late evacuees pose multiple challenges for fire agencies. An application of analytics and decision support system, capable of computing J ust-in-time allocation of resources, can enhance the capacity of fire services agencies. Using the multi-objective analytics, this paper therefore develops optimal resource allocation models to enhance emergency response to improve the efficiency of late evacuation response.
\end{abstract}

Three key operational challenges are tackled including timely evacuation, shelter assignment and routing. Three bushfire scenarios are constructed to incorporate constraints of restricted time-window and potential road disruptions. Capacity and number of rescue vehicles and shelters are other constraints. This mathematical model is solved by the application of the $\varepsilon$ constraint approach. Objective functions are simultaneously optimised to maximise the total number of evacuees while minimise the number of assigned rescue vehicles and shelters. We argue that this model provides a scenario-based decision-making tool to aid maximise the resource utilisation and coverage of late evacuees. The analytics based insights drawn from various disruption scenarios could help emergency services agencies in identifying appropriate strategies to improve the efficiency of late evacuation response.

Keywords: Bushfire, Late Evacuation, Multi-Objective Optimisation, Emergency Management

\section{Introduction}

Bushfire is one of the most prevalent natural hazards in Australia. A bushfire is "a freely burning, uncontrolled and unplanned fire, which needs to be extinguished" (CFA Definitions 2012). In recent years, there has been a substantial increase in the number of bushfires around the world (Cameron et al. 2009). Global warming and climate change have potentially 
increased the risk of bushfire, particularly in peak seasons in many countries including Australia (Teague et al. 2009), USA (Westerling et al. 2006), Canada (Podur et al. 2002) and Russia (Kharuk et al. 2007).

Bushfire is a threat to communities, particularly those who live in bushfire-prone areas. Every year, bushfires (also referred as wildfire) cause significant financial and human losses (Butry et al. 2001). Although direct and indirect costs are difficult to estimate, there are three cost components: loss of human life and injury; economic costs; and damage to the ecosystem. The Bushfires Royal Commission has estimated the cost of the Black Saturday disaster to be \$4.4 billion, along with 173 lives lost (Teague et al. 2009). Due to the significance of bushfire hazards to Australia, much research is conducted in a variety of research areas including environment impact assessment, risk mitigation, community resilience and cost estimation (Cameron et al. 2009; Church and Cova 2000; Ellis et al. 2004; Lindell and Perry 2003). However, the late evacuation of residents from bushfire-affected areas has attracted much less research attention in Australia until recent years.

Applications of innovative optimisation techniques and analytics would help fire agencies in improving the operational response to bushfire emergency. This will in turn help saving lives and prevent injuries as well as reducing economic costs through a better utilisation of scarce resources. One of the key challenges in bushfire events is the operational capacity to design an efficient and effective evacuation plan from bushfire-prone areas to shelters within a restricted time windows with finite resources. Bushfire tends to disrupt the emergency supplies and transportation networks, which in turn makes the transfer of late evacuees difficult. For example, bushfire propagation rate increases twice with every 10-degree increase in slope and the bushfire spread doubles with a small change in wind speed. The temperature reaches to 800-degree celsius during a bushfire (Whittaker et al. 2009), and the flames crown attained a height of about 30 meters (Victorian Bushfires Royal Commission Report 2009). As in the case of the Black Saturday bushfire in Victoria, late evacuation has proven to be extremely hazardous and lethal (Victorian Bushfires Royal Commission Report 2009). Late emergency evacuation in dynamic bushfire conditions, therefore, requires a robust modelling and analytic capability that consider the simultaneous optimisation of multiple objectives and constraints. Such decision support tool should be capable of dynamically selecting a shelter, assigning each evacuee to a shelter, maximise spatial coverage, and determine the optimal routing. Thus, it involves solving four key problems: allocation, assignment, spatial coverage and routing.

Designing of a robust system is dependent on human behaviour and response to a threat. Thus, the decision to stay or leave early in a bushfire is a critical to community safety. People those expose to fire risk may decide to leave early, or take shelter-in-home or shelter-in-refuge (Cova et al. 2011). Obviously, early evacuation is the safest option to protect life. Nevertheless, there are some residents who prefer to stay and protect their properties. There are also those who leave at the last minute (Victorian Bushfires Royal Commission Report 2009). The late evacuation exposes the evacuees to radiant heat, which has been found a key factor in human fatalities (Teague et al. 2009). Late evacuation often increases the risk of injury or death.

Studies that have contextualised the bushfire emergency evacuation considering Australian bushfire emergency policy context to tackle the key operational challenges including timely evacuation, shelter assignment and routing are rather rare (Shahparvari et al. 2015a; Shahparvari et al. 2015b). This research bridges the gaps by developing a reliablemathematical model, which aims to maximise the number of evacuated late evacuees within the restricted time windows (clearance time) via shortest risk routes. The proposed model also is capable of allocating the optimal utilisation of the available resources such as accessible shelters and vehicles. This model has been implemented as a two-step framework with the application of the $\varepsilon$-constraint method. The main contributions of the model are summarised as follows:

- Alignment to provide evidence to assess the "Stay or Go recommendation" policy, which has been developed based on many years of past experience. 
- The formulation of a novel capacitated mixed-integer multi-objective optimisation problem with time windows which is capable of generating and enhancing the requirement of quick responses and prioritising shipments during emergency evacuations.

- The ability of the model to handle complex capacitated multi-location, multi-vehicles types under multi-time windows problems using a multi-objective optimisation modelling framework.

- The application of the analytical tool to a real-world case study a bushfire.

The remainder of the paper is organised as follows. The next section reviews relevant literature in the area of bushfire evacuation planning. Then, the problem statement is described followed by problem assumptions. The developed mathematical formulation and the solution approach are presented in the subsequent sections. The effectiveness of the model will be assessed and discussed by implementing a range of bushfire scenarios. The paper concludes with presenting a summary of the key findings.

\section{Literature Review}

Evacuation is the process of "relocation from areas at risk to areas of greater safety" (Southworth 1991; Zelinsky and Kosiński 1991). In other word, an evacuation is a process of transferring people from assembly points to safe shelters within the close vicinity. Evacuation is a complex process, which entails operations required across different phases (Figure 1). Evacuation process during a disaster can be categorised as pre-disaster, during-disaster and post-disaster phase. The pre-disaster is the initial phase of detecting an incident and make the decision to stay or leave before the disaster begins to threaten people's lives. During-disaster phase includes five stages that should be carried out. It in this phase when risks and potential threats in specific areas are estimated by decision makers prior to issuing an evacuation order (Lindell 1995). In Phase III, the communities at risk are alerted with early warning. In phase IV, a decision to stay or evacuate is made by residents, which leads to the preparation for evacuation. In the next phase, transfer of people to safe areas or shelter occurs. This phase implies clearing of affected people from hazardous zones.

In the penultimate Phase, people at risk are transferred to shelters outside of hazardous areas. As shown in Figure 1, the response time (clearance time), which includes phase five and six, is one of the main critical factors that plays a key role in evacuation processes. This study therefore focuses on these phases to enhance the evacuation response time. At last, and in the third category as post-disaster processes and at the final phase, verification and auditing are carried out to ensure that evacuees are evacuated to safe places.

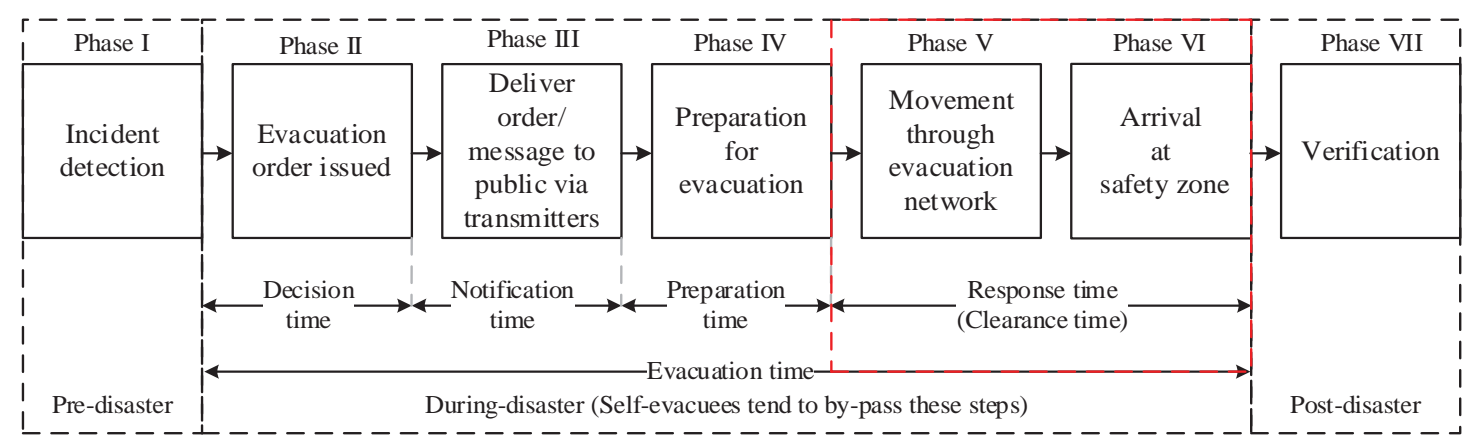

Figure 1- Evacuation Phases (Source: adapted from Lindell, 1995)

In the event of bushfire, residents' responses can be categorised into three groups; those who leave early; those who stay at their properties (Shelter in Refuge) and those who decide to shelter in the refuge. Cova et al. (2011) referred these decision-choices as the 'protective actions' (Figure 2). Bushfire evacuation can be mandatory, recommended, or voluntary. In most countries, evacuation during a bushfire is compulsory. In Australia and southern parts of 
France a stay or go choice is given to residents except in the case of a severe bushfire (Arnol 2007). People have the choice to leave early, or stay at home and protect their properties (Shelter-in-place). Some residents with disability, elderly, and parents with children, however, require additional support; whilst others might not have access to a personal vehicle.

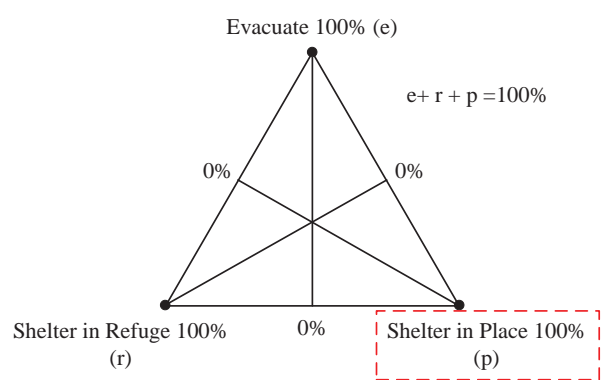

Figure 2 - Protective Actions Ternary Diagram (source: Cova et al., 2011)

In Australia, the "Stay or Go" policy transfer the responsibility and decision of staying and protecting the property or leave early to individuals. The current Australian 'Stay or Go' policy, which is a replacement of previous plan 'prepare', stay and defend, or leave early', has strategically design to reduce risk to government agencies by making people responsible for their actions (Paveglio et al. 2008). One key limitation of this policy in Victoria is the lack of consideration for late evacuees who are not well integrated into the evacuation procedures (Teague et al. 2009). The policy emphasizes the importance of timely evacuation and condemned the policy of prepare and protect. An early evacuation is desirable and is most preferred option to minimise risk in a bushfire. Similarly in the United States, the "Ready, Set, Go" (RSG) policy is in use, which provides information on when and how to prepare and evacuate or take refuge in a shelter. People who decided to stay and protect their properties in an extreme weather required an efficient and effective emergency response. Hence, planning and resourcing are the key issues in emergency management.

The evacuation problem has traditionally been solved as an optimization problem that minimises/maximises a certain objective function subject to supply, demand and time constraints. Numerous objective functions have been formulated in theliterature with the goal of expediting the evacuation process. In comprehensive research, Cohon (2004) identified some objectives, such as clearance time, the number of an evacuee, and resources, which should be considered in decision making. While the early evacuation occurs by car (Pel et al. 2012), however, the late evacuation has to be carried out using high-capacity vehicles such as buses to transfer people to shelters (Vuchic 2005). Although, real-time location-allocation and routing of late evacuees to shelters are subject to a range of other objectives, including capacities, distances, and susceptibility or vulnerability to the disaster, which should also be simultaneously optimised while operating within a range of stringent constraints. ( $\mathrm{Li}$ et al. 2012; Negreiros and Palhano 2006). Nevertheless, the most challenging objective of emergency situation management is cited as the quick and safe transportation of late evacuees to shelters within a very tight time window. To deal with such a problem, the key questions required to be tackled including when, where, and how to safely transfer the late evacuees from assembly points within a short time window under stringent conditions?

Real-time assignment of evacuees to a shelter is affected by a range of factors, including its capacity, distance, and susceptibility or vulnerability to the hazard ( Li et al. 2012; Negreiros and Palhano 2006). Furthermore, other objectives should also be simultaneously optimised while operating within a range of constraints. Allocation of shelters, in terms of optimal location, number and capacity, is critical to emergency planning (Alexander 2000). A number of studies have developed mathematical formulations to discuss transit-based evacuation under both unpredictable (e.g., earthquake; see (Sayyady 2007)) and predictable (e.g., cyclone; (Chan 2010; Margulis et al. 2006)) disasters. In addition, several studies consolidated location-allocation problem with routing problem (Chan 2010; He et al. 2009; Mastrogiannidou et al. 2009). Concerns over unplanned evacuation resources such as lack of 
rescue vehicles, shelters availability that may be a reflection of uncoordinated pre-emergency planning. Furthermore, sufficient attention has not been given to the integration of transitbased systems with the emergency evacuation location-allocation in the frame of OR/MS (Operations Research/Management Science). The focus of this research is therefore on analysing the operational aspects of the late evacuation process, that is, the transfer of people from assembly points to the designated shelters.

In conclusion, there are only a few studies that have employed multi-objective optimisation models for late evacuation problems (Shahparvari et al. 2015a; Stepanov and Smith 2009). The majority of studies have focused on minimising the total evacuation time without considering other objectives such as resource utilisation or area coverage. Therefore, this study aims to apply an optimisation approach to deal with the multi-objective evacuation problem to generate the possible solutions to improve emergency evacuation planningin case of bushfires.

\section{Mathematical Formulation}

A typical evacuation problem contains various objective functions, uncertainties and constraints, which makes the multi-objective programming method much more appropriate. Hence, in this paper, a Multi-Objective (MP) method is utilised to formulate the problem.

\subsection{Modelling Assumptions}

For initialising model parameters, the following assumptions are set out to represent bushfire emergency evacuation conditions.

- Shelters are pre-designated by Country Fire Authority.

- Number and capacity of shelters and rescue vehicles are finite.

- The late evacuee population in each assembly point are known from real population data.

- Evacuees can be transferred to more than one shelter.

- Access to some routes is restricted by bushfire.

- The transfer time between assembly points and shelters is known and computable.

\subsection{Notations}

i Index for assembly points (townships and origins);

j Index for candidate shelter areas (safe places or destinations);

$\mathrm{k} \quad$ Index for vehicle types;

I Set of assembly points;

$\mathrm{J} \quad$ Set of candidate places of shelters;

\subsubsection{Parameters}

$\mathrm{Cap}_{\mathrm{j}}$ Capacity of shelter $\mathrm{j}$;

$\mathrm{D}_{\mathrm{i}} \quad$ Population of people (late evacuees) in assembly point $\mathrm{i}$ to be evacuated;

$\alpha_{\mathrm{j}} \quad$ Binary variable; 1 if shelter $\mathrm{j}$ is accessible, 0 otherwise;

$\beta_{\mathrm{ij}} \quad$ Binary variable; 1 if road is not disrupted between assembly point $\mathrm{i}$ and shelter $\mathrm{j}, 0$ otherwise.

$t_{i j} \quad$ Estimated transportation time between assembly point (township) $i$ and shelter $j$;

$\mathrm{p} \quad$ Total maximum number of required shelters;

$\mathrm{TV}_{\mathrm{k}}$ Total maximum number of vehicle type $\mathrm{k}$;

$\mathrm{VC}_{\mathrm{k}} \quad$ Capacity of vehicle type $\mathrm{k}$; 
$\mathrm{TW}_{\mathrm{i}} \quad$ Time window for evacuation people from assembly point i;

$\mathrm{Q}_{\mathrm{k}} \quad$ Usage cost of vehicle type $\mathrm{k}$;

W Weighted sum coefficient

\subsubsection{Decision Variables}

$\mathrm{X}_{\mathrm{ij}} \quad$ Denotes the number of affected people transferred from the assembly point $\mathrm{i}$ to the designated shelter $\mathrm{j}$

$N V_{i j}^{k} \quad$ Denotes the number of rescue vehicles type $\mathrm{k}$ that is required to be utilised in order to transfer the evacuees from assembly point $i$ to shelter $\mathrm{j}$.

\subsubsection{Auxiliary Decision Variables}

$Y_{j} \quad$ (Binary variable) If it is possible to transfer the evacuees to the designated shelter $\mathrm{j}$ it takes 1 and 0 otherwise.

$\mathrm{S}_{\mathrm{j}} \quad$ (Binary variable) If a candidate shelter $\mathrm{j}$ is assigned to serve the evacuees, it takes 1 and 0 otherwise.

\subsection{Objective Functions}

The following two objective functions are optimised simultaneously subject to constraints on resources and network structure:

- To maximise the number of people transferred to a designated shelter within the defined time windows

- To minimise usage of number of available resources (i.e. the number of assigned shelters and rescue vehicles).

\subsection{Mathematical Model}

The developed formulation as a multi-objective model comprises two objective functions and a range of constraints as follows:

$\operatorname{Max} f_{1}=\sum_{i} \sum_{j} X_{i j}$

The first objective function shown in (1), maximises the number of evacuees assembled in assembly point $i$ which must be transferred toward shelter $\mathrm{j}$ in minimum time and across the shortest route.

$\operatorname{Min} f_{2}=W_{1} \sum_{j} S_{j}+W_{2} \sum_{i} \sum_{j} \sum_{k} Q_{k} N V_{i j}^{k}$

The second objective function (2) minimises total number of designated shelters and rescue vehicles. This goal is set to decrease expenditures of allocating new facilities and to distribute evacuees by utilisation of minimum available shelters and rescue vehicles. $\mathrm{w}_{1}$ and $\mathrm{w}_{2}$ as auxiliary coefficients, are utilised as a weighted sum method and are selected in the range of $(0,1)$ to represent weight of impression for each parameter (i.e. shelter and vehicle).

\subsection{Constraints}

The objective functions are subject to the following constraints:

$\sum_{j} Z_{j} \leq p$

Constraint (3) ensures that the number of allocated shelters is less than number available shelters.

$Y_{j} \leq \alpha_{j} S_{j}$

Constraint (4) determines if it is possible to assign a shelter $\left(\mathrm{Y}_{\mathrm{j}}\right)$ among all possible candidate places $\left(\mathrm{S}_{\mathrm{j}}\right)$.

$\sum_{i} X_{i j} \leq \operatorname{Cap}_{j} Y_{j}$ 
Constraint (5) ensures that people at assembly point i would be transferred to shelter j, only if the shelter $j$ is accessible and available. Also, this constraint measures that transferred people to shelter $j$ does not exceed the shelter capacity.

$X_{i j} \leq \beta_{i j} D_{i}$ $\forall i, j$

Constraint (6) defines that people at assembly point i can be transferred to shelter $\mathrm{j}$ if the connective road between $i$ and $j$ is accessible and available.

$\left(2 \times t_{i j}\right) X_{i j} \leq T W_{i} \sum_{k} V C_{k} N V_{i j}^{k} \quad \forall i, j$

Constraint ( 7$)$, as time window constraints expresses that total evacuation time $\left(2 \times \mathrm{t}_{\mathrm{ij}}\right)$ of each assembly point i should not be more than its available time window considering available rescue vehicles and their limited capacities.

$\sum_{i} \sum_{j} N V_{i j}^{k} \leq T V_{k} \quad \forall \mathrm{k}$

Constraint (8) measures the numbers of allocated rescue vehicle typek to transfer people from each assembly point $i$ to shelter $j$ to not exceed the total number of available vehicles.

$\sum_{j} X_{i j} \leq D_{i}$

$\forall \mathrm{i}$

Constraint (9) restricts the number of transferred peopled from assembly point $i$ to shelters $j$ to their capacities.

$X_{i j}, N V_{i j}^{k} \geq 0$

$$
\forall \mathrm{i}, \mathrm{j}, \mathrm{k}
$$

Constraint (10) expresses the negative numbers could not be considered for the integer variables.

$S_{j}, Y_{j}=0$ or 1

Constraint (11) restricts the assignment of shelters and transferring issues to binary values, as $\mathrm{S}_{\mathrm{j}}, \mathrm{Y}_{\mathrm{j}}$ are either allocated or not.

\section{Case Study: Lake Eildon National Park}

The problem is formulated and applied to a real case study of a bushfire prone area in Northeast of Victoria in Australia. The area of study contains six townships (Eildon, Thornton, Mainton, Alexandra, Acheron, and Bonnie), which are located near the Lake Eildon national park. With a total population of about 1036 people, this hilly region is thus not densely populated. Based on theanalysis carried out by CFA, approximate one-third (33\%) of residents were affected by the Black Saturday Bushfires, majority of which could be deemed late evacuees (Teague et al. 2009). Four potential safer townships (i.e. Taggerty, Merton, Yarck, and Yea) are nominated by CFA to shelter late evacuees during an emergency evacuation situation. Shelters are assumed to have a finite capacity to accommodate the evacuees (Table 1) (e.g. the Merton public cricket ground oval can shelters 450 persons).

Real transportation network and travel time between the townships are computed. Therefore, the travel time between any two nodes the network are calculated based on real distances and travel speed zones. Shelters availability and roads connectivity are affected by the direction and path of bushfires. Hence, time windows are defined to prioritise the bushfire arrival time. Time windows are calculated on the basis of wind direction and distance between bushfire ignition point and townships using the average bushfire spread rate, which is approximately 20 kilometres per hour (Teague et al. 2009). Also, two different types of vehicles (Bus can carry 40 and Van 10 people) are incorporated. For the base case, 20 buses and 30 vans are available to be assigned to gain the optimal routing process. Also, to balance vehicles assignment, a usage cost for each type of vehicle is considered as 100 financial unit for bus and 40 for the van. 


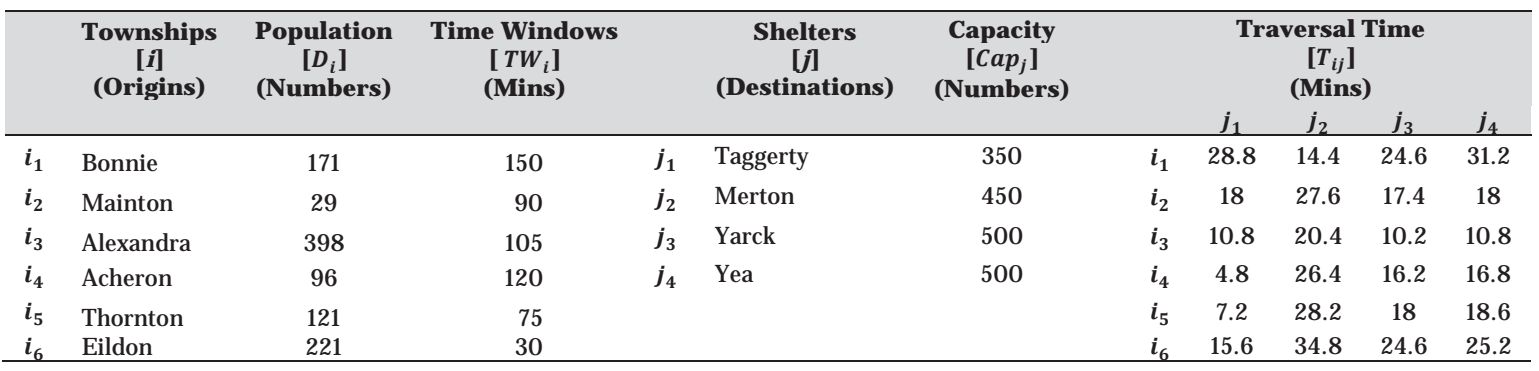

Table 1- Summary of Inputs and Assumptions

\subsection{Development of Bushfire Scenarios}

Three comprehensive What-IF bushfire scenarios are considered. It ranges from a simple through to more complex bushfire scenarios, as described in Table 2.

\begin{tabular}{|c|c|c|c|}
\hline Bushfire Scenario & Intensity & Wind Direction and Road Conditions & Road Disruptions \\
\hline Bushfire Scenario A & Low & $\begin{array}{l}\text { South-eastern to north-western wind direction } \\
\text { spreads the bushfire and disrupts } 2 \text { roads }\end{array}$ & $\begin{array}{l}\boldsymbol{i}_{\mathbf{1}} \rightarrow \boldsymbol{j}_{\mathbf{1}} \text { (Northern Mainton Rd) } \\
\boldsymbol{i}_{\mathbf{6}} \rightarrow \boldsymbol{j}_{2} \text { (Back Eildon Rd) }\end{array}$ \\
\hline Bushfire Scenario B & Medium & $\begin{array}{l}\text { Wind direction changes to East - west and } \\
\text { restricts } 4 \text { main roads }\end{array}$ & $\begin{aligned} \boldsymbol{i}_{1} & \rightarrow \boldsymbol{j}_{1} \text { (Northern Mainton Rd) } \\
\boldsymbol{i}_{2} & \rightarrow \boldsymbol{j}_{2} \text { (Southern Mainton Rd) } \\
\boldsymbol{i}_{5} & \rightarrow \boldsymbol{j}_{4} \text { (Goulburn Valley Hwy) } \\
\boldsymbol{i}_{6} & \rightarrow \boldsymbol{j}_{2} \text { (Back Eildon Rd) }\end{aligned}$ \\
\hline Bushfire Scenario C & High & $\begin{array}{l}\text { Bushfire Spotted in three different points and as a } \\
\text { result of a north-eastern to south-western wind } \\
\text { direction, } 7 \text { roads are disconnected }\end{array}$ & $\begin{aligned} \boldsymbol{i}_{1} & \rightarrow \boldsymbol{j}_{1} \text { (Northern Mainton Rd) } \\
\boldsymbol{i}_{1} & \rightarrow \boldsymbol{j}_{2} \text { (Maroondah Hwy) } \\
\boldsymbol{i}_{2} & \rightarrow \boldsymbol{j}_{3} \text { (Southern Mainton Rd) } \\
\boldsymbol{i}_{2} & \rightarrow \boldsymbol{j}_{4} \text { (Mainton Rd) } \\
\boldsymbol{i}_{5} & \rightarrow \boldsymbol{j}_{1} \text { (Taggerty-Thornton Rd) } \\
\boldsymbol{i}_{5} & \rightarrow \boldsymbol{j}_{2} \text { (Goulburn Valley Hwy) } \\
\boldsymbol{i}_{6} & \rightarrow \boldsymbol{j}_{2} \text { (Back Eildon Rd) }\end{aligned}$ \\
\hline
\end{tabular}

Table 2 - Bushfire What-IF Scenarios

Also, Figure 3 illustrates the bushfire scenarios accompanied by bushfire-spread isochrones. 

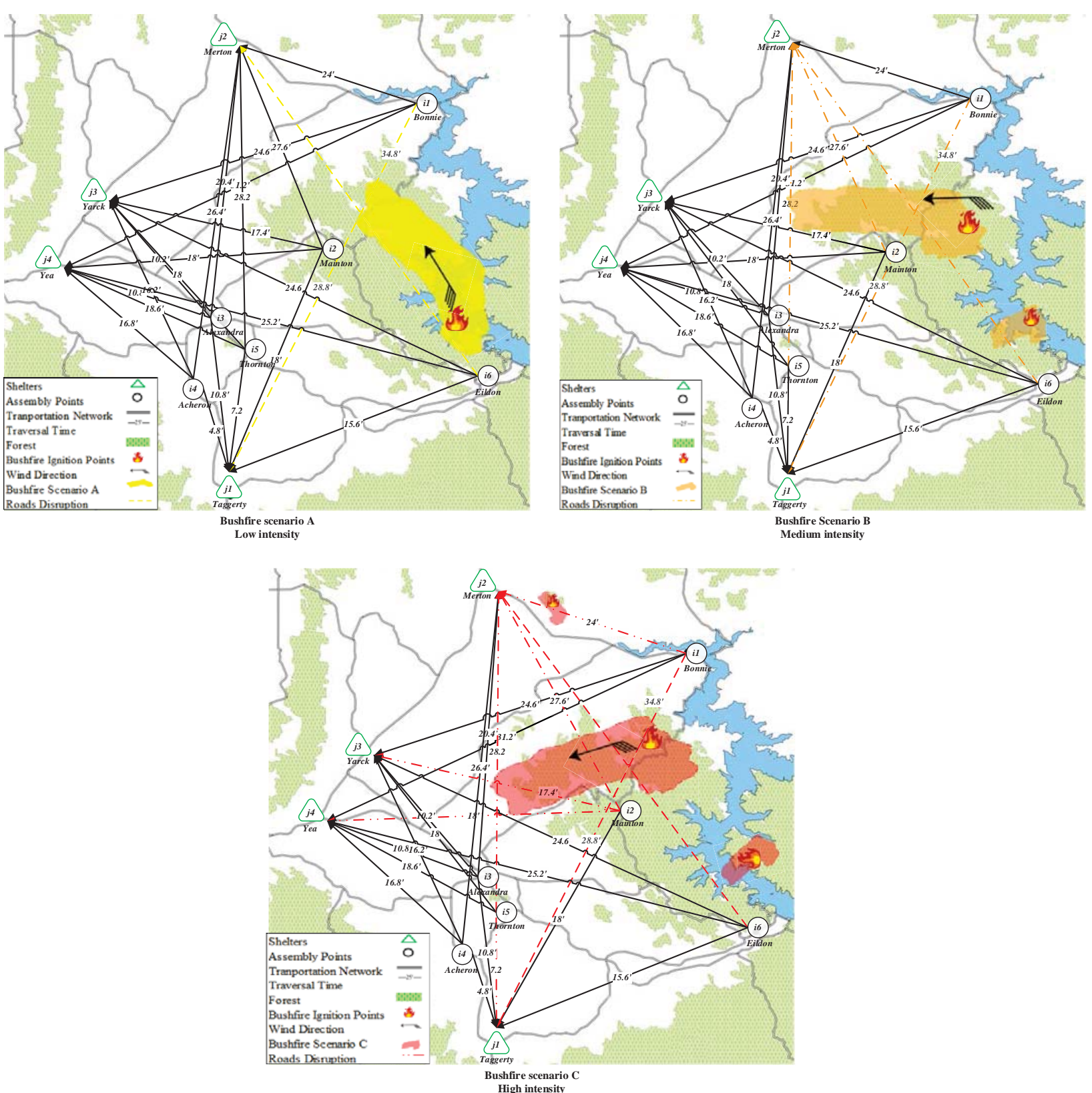

Figure 3 - Bushfire Scenarios

\section{Solution Approach}

The multi-objective mixed-integer problem solutions are not typically straightforward. In other words, there is not generally a feasible absolute optimal solution enables to optimise all objective functions concurrently (Ehrgott 2006). To take such a problem, Pareto-optimal solutions have attracted much more attentions that typically referred to as "a posteriori" or "non-dominated solution generation". Pareto front optimal solutions are sort of common MOIPs (Multi-Objective Integer Problems) solution approaches that attempt to optimise the main objective by degrading at least one of the other objectives.

The Epsilon constraint method is sort of common Pareto front solution techniques, which has been widely employed to solve similar mixed integer multi-objective problems (Vira and Haimes 1983). In this approach, the main objective of problem out of $n$ is chosen as to be optimised while remaining objectives are converted into form of inequality constraints by assigning allowable levels of epsilon as an upper or lower bound given target values. All other objective functions will be minimised while are constrained to the first objective function value. Therefore, this method provides a vast range of flexibility for the decision makers by varying 
the lower or upper bounds $\varepsilon$ to achieve Pareto optima (Zitzler and Thiele 1998). In mathematical terms, decision maker let $\mathrm{f}_{\mathrm{n}}(\mathrm{x})$ be the objective function selected among $\mathrm{M}$ objective functions to be optimised, the multi-objective problem is transformed as follows:

$\operatorname{Max} f_{n}(x)$

$x \in S$

$f_{p}(x) \geq \varepsilon_{\boldsymbol{p}}$

$$
\forall \mathrm{p} \in\{1,2, \ldots, \mathrm{M}\}
$$

Where $\mathrm{S}$ is feasible solution space. Therefore and given all of these, the Epsilon constraint approach was chosen as an efficient method to solve the research problem.

In this paper model, the main objective is set to save more human lives and evacuate more people within the time windows. Therefore, the first objective $f_{1}$ is chosen as the main objective to be optimised, while, $f_{2}$ is converted into a hard constraint by the application of the $\varepsilon$ constraint method. Respectively in the next step, the second objective function will be minimised.

Step 1: This step aims to evacuate the entire evacuee population by minimising the number of assigned shelters and rescue vehicles within the bushfire-prone areas. Hence, the model will solve considering the objective function $\mathrm{f}_{2}$ as hard constraint of covering the entire evacuee population. The output of this step determines preliminary minimised values for parameters of $\mathrm{S}_{\mathrm{j}}$ as number of required shelters and $N V_{i j}^{k}$ as number of required rescue vehicles that required evacuating all the evacuees. Respectively, these initial values will be used as an upper bond in the next step to calculate the optimal values. The model formulation will be converted as follows:

$$
\operatorname{Max} f_{1}(x)
$$

Subject to Constraints $(3,4,5,6,7,8,10,11)$

$$
\sum_{j} X_{i j}=D_{i} \quad \forall \mathrm{i}
$$

Step 2: This step optimises the initial values for allocated resources while maximising the number of evacuated people. Hence, values for number of required shelters $\left(\mathrm{S}_{\mathrm{j}}\right)$ and rescue vehicles $\left(N V_{i j}^{k}\right)$, which were obtained from the previous step will be used as a upper bond for total number of shelters $(\mathrm{p})$ and total number of available vehicle type $\mathrm{k}\left(T V_{k}\right)$. In reality the value of $\mathrm{p}$ and $T V_{k}$ are usually known and given by the fireagencies based on maximum available budget, resources and capacities. It is obvious that by given the preliminary values for these parameters, the first step is not necessarily required. So the preliminary values of the aforementioned parameters are set in the constraints. Also, $\varepsilon$ penalty value is considered to adjust the constraints (equation 12 ). Consequently, the proposed multi-objective model is converted into the following single-objective problem:

$$
\begin{aligned}
& \boldsymbol{M i n} f_{2}(\mathrm{x}) \\
& \text { Subject to } f_{1}(x) \geq \varepsilon_{\boldsymbol{p}} \\
& \text { The value of } \varepsilon_{\boldsymbol{p}} \text { is determined as follows: } \\
& \varepsilon_{\boldsymbol{p}}=\boldsymbol{\Omega} \cdot \sum_{i} \sum_{j} X_{i j}
\end{aligned}
$$

Here $\Omega \in[0,1]$ indicates the maximum percentage of total penalty. In this problem, the $\Omega$ value is selected randomly in the range of $(0.4,0.9)$ at the discretion of decision makers. Besides, value of p is set by multiplying $\Omega$ by theinitial value of $\mathrm{S}_{\mathrm{j}}$. Respectively, $T V_{k}$ is calculated by multiplying of $\Omega$ by the initial value of $N V_{i j}^{k}$.

\section{Results and Analysis}

The main aim of this section is to demonstrate how the proposed methodical formulation can be utilised to improve the performance of the evacuation process in an emergency situation to 
save lives of more human beings. Therefore, a real case study in three bushfire scenarios was comprehensively examined and presented to demonstrate the problem methodology. Also, Sensitivity analysis against changing the key parameters such as number of required vehicles and number of assigned shelters is provided. Furthermore, the shelter capacity usage in each scenario is investigated is this section. The model was implemented using the CPLEX solver 12.6. According to the proposed solution approach, the outputs are as follows:

\section{Step 1: Preliminary number of available resources (shelters and rescue vehicles)}

The objective value for the first step solution is 87.9 that represents the minimised cumulative value of assigning facilities and resources to evacuate the evacuees entirely. Also, the preliminary output of the solving model in this step indicates that all 4 available shelters $\left(j_{1}, j_{2}\right.$, $\mathrm{j}_{3}$, and $\mathrm{j}_{4}$ ) should be utilised to cover the evacuation demand of late evacuee population within the time windows. Besides, results show that at least 23 rescue vehicles including 13 Buses and 10 Vans are required to transfer all the evacuees. In this case study, the optimal output was obtained by assuming 0.95 for parameter $\mathrm{w}_{1}$ and 0.05 for $\mathrm{w}_{2}$. Obviously the higher assigned value for w lead to stronger impact of the associated parameter in the model.

\section{Step 2: Optimal number of shelters, vehicles and routing}

\subsection{Optimal evacuees' transportation to the assigned shelters}

In this step, the model is solved while is constrained to the preliminary values of required resources values that were achieved in the first step. Table 3 represents the optimal distribution of evacuees within the accessible routes in transportation network in each scenario. Respectively, Table 3 represents the optimal assignment of the required vehicles followed by the number of required trips to evacuate the evacuee population.

\begin{tabular}{|c|c|c|c|c|c|c|c|c|c|c|c|c|c|c|}
\hline \multicolumn{5}{|c|}{$\begin{array}{c}\text { Bushfire Scenario A } \\
\text { Low Intensity }\end{array}$} & \multicolumn{5}{|c|}{$\begin{array}{l}\text { Bushfire Scenario B } \\
\text { Medium Intensity }\end{array}$} & \multicolumn{5}{|c|}{$\begin{array}{c}\text { Bushfire Scenario C } \\
\text { High Intensity }\end{array}$} \\
\hline \multicolumn{5}{|c|}{$X_{i j}$ (Evacuated people) } & \multicolumn{5}{|c|}{$X_{i j}$ (Evacuated people) } & \multicolumn{5}{|c|}{$X_{i j}$ (Evacuated people) } \\
\hline & $j_{1}$ & $j_{2}$ & $j_{3}$ & $j_{4}$ & & $j_{1}$ & $j_{2}$ & $j_{3}$ & $j_{4}$ & & $j_{1}$ & $\boldsymbol{j}_{2}$ & $j_{3}$ & $j_{4}$ \\
\hline$i_{1}$ & 0 & 100 & 71 & 0 & $i_{1}$ & 0 & 100 & 0 & 71 & $i_{1}$ & 0 & 0 & 100 & 71 \\
\hline$i_{2}$ & 0 & 29 & 0 & 0 & $i_{2}$ & 29 & 0 & 0 & 0 & $i_{2}$ & 29 & 0 & 0 & 0 \\
\hline$i_{3}$ & 100 & 100 & 100 & 98 & $i_{3}$ & 100 & 100 & 100 & 98 & $i_{3}$ & 100 & 100 & 100 & 98 \\
\hline$i_{4}$ & 96 & 0 & 0 & 0 & $i_{4}$ & 0 & 0 & 96 & 0 & $i_{4}$ & 0 & 0 & 96 & 0 \\
\hline$i_{5}$ & 52 & 0 & 0 & 69 & $i_{5}$ & 100 & 0 & 0 & 21 & $i_{5}$ & 0 & 0 & 41 & 80 \\
\hline$i_{6}$ & 76 & 0 & 97 & 48 & $i_{6}$ & 100 & 0 & 21 & 100 & $i_{6}$ & 100 & 0 & 97 & 24 \\
\hline 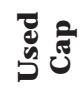 & 324 & 229 & 268 & 215 & 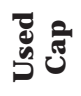 & 329 & 200 & 217 & 290 & 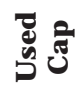 & 229 & 100 & 434 & 273 \\
\hline \multicolumn{5}{|c|}{$S_{j}$ (Shelters Assignment) } & \multicolumn{5}{|c|}{$S_{j}$ (Shelters Assignment) } & \multicolumn{5}{|c|}{$S_{j}$ (Shelters Assignment) } \\
\hline & $\begin{array}{r}\boldsymbol{j}_{1} \\
1\end{array}$ & $\begin{array}{r}\boldsymbol{j}_{2} \\
1\end{array}$ & $\begin{array}{r}j_{3} \\
1\end{array}$ & $\begin{array}{r}j_{4} \\
1\end{array}$ & & $\begin{array}{r}j_{1} \\
1\end{array}$ & $\begin{array}{r}j_{2} \\
1\end{array}$ & $\begin{array}{r}j_{3} \\
1\end{array}$ & $\begin{array}{r}j_{4} \\
1\end{array}$ & & $\begin{array}{r}j_{1} \\
1\end{array}$ & $\begin{array}{r}\boldsymbol{j}_{2} \\
1\end{array}$ & $\begin{array}{r}j_{3} \\
1\end{array}$ & $\begin{array}{r}j_{4} \\
1\end{array}$ \\
\hline
\end{tabular}

Table 3 - Optimal Evacuation Plan to the Assigned Shelters

As it is shown in Table 3, Eildon ( $\mathrm{i}_{6}$ ) has the minimum time window and people should be evacuated within 30 minutes before bushfire reaches there. Therefore, in bushfire scenario A, Merton $\left(\mathrm{j}_{2}\right)$ is not accessible and there are no transportation to there. The optimal plan for this township is to transfer 76 people to Taggerty $\left(j_{1}\right), 97$ people to Yarck $\left(j_{3}\right)$ and the rest of 48 evacuees to Yea $\left(\mathrm{j}_{4}\right)$. In scenario B, bushfire intensity is medium and Goulbourn valley highway and Mainton road also are blocked. Regarding to the new road disruptions and scenario's constraints as time windows, shelter capacities and vehicles availability, the optimal emergency evacuation plan is to evacuate 100 people to shelter $j_{1}, 21$ people to $j_{3}$ and rest of 100 people to shelter $\left(\mathrm{j}_{4}\right)$. Respectively, the optimal evacuation routing plans for other hazardous townships are presented in Table 3. Also, Figure 4 visualises the optimal emergency evacuation routing and distribution of late evacuees in each scenario. 

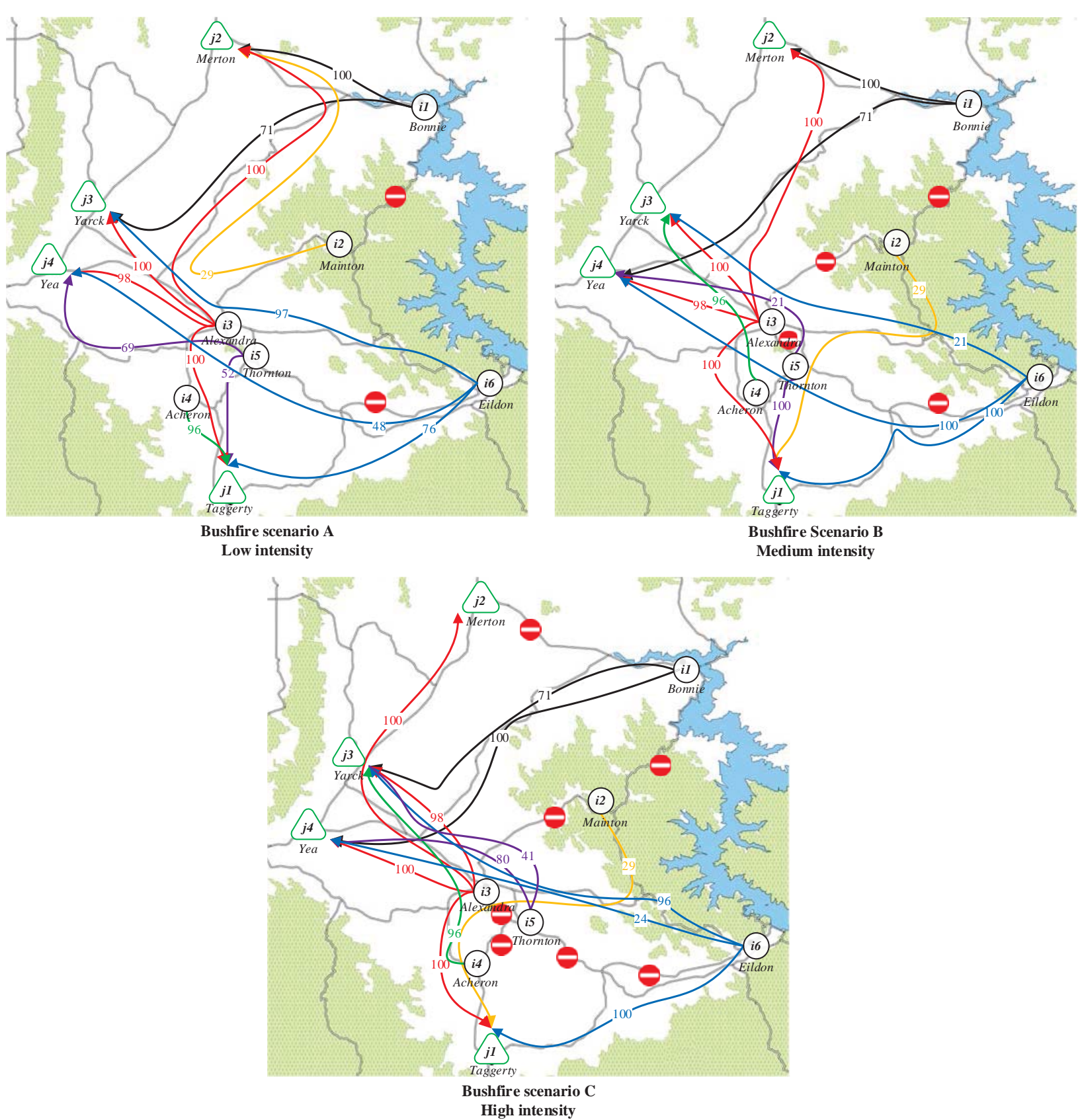

Figure 4 - Optimal Evacuation Routing Plan

\subsection{Optimal number of assigned rescue vehicles and trips}

Respectively, Table 5 represents the optimal assignment of vehicle and number of trips that are required to evacuate the late evacuee population. For example, in scenario A, Eildon has the shortest time window. Therefore, 2 buses are assigned to transfer 76 evacuees from Eildon $\left(i_{6}\right)$ to Taggerty $\left(j_{1}\right)$. Accordingly, 97 people are transported to Yarck $\left(j_{3}\right)$ by 4 buses in one-way trip and the rest of 48 evacuees are evacuated by assignment of 2 buses and 1 van traveling 1 and 5 times between Eildon $\left(\mathrm{i}_{6}\right)$ and Yea $\left(\mathrm{j}_{4}\right)$ simultaneously to transfer Eildon population within the 45 minutes predefined time window. As it can be realised from the results, due to the predefined route disruption in the Northern Mainton road, evacuees could not be transferred to Merton $\left(\mathrm{j}_{2}\right)$. In the scenario B, 100 people are evacuated to Taggerty $\left(\mathrm{j}_{1}\right)$ by assignment of 3 buses trip 3 times while 1 bus is assigned to serve evacuation process from $i_{6}$ toj $j_{3}$. 


\begin{tabular}{|c|c|c|c|c|c|c|c|c|c|c|c|c|c|c|}
\hline \multicolumn{5}{|c|}{$\begin{array}{c}\text { Bushfire Scenario A } \\
\text { Low Intensity }\end{array}$} & \multicolumn{5}{|c|}{$\begin{array}{c}\text { Bushfire Scenario B } \\
\text { Medium Intensity }\end{array}$} & \multicolumn{5}{|c|}{$\begin{array}{c}\text { Bushfire Scenario C } \\
\text { High Intensity }\end{array}$} \\
\hline \multicolumn{5}{|c|}{$N V_{i j}$ (Number of Vehicles) } & \multicolumn{5}{|c|}{$N V_{i j}$ (Number of Vehicles) } & \multicolumn{5}{|c|}{$N V_{i j}$ (Number of Vehicles) } \\
\hline$i_{1}$ & $\begin{aligned} \boldsymbol{j}_{1} \\
0\end{aligned}$ & $\begin{array}{l}\boldsymbol{j}_{2} \\
2 \mathrm{~V}\end{array}$ & $\begin{array}{l}j_{3} \\
1 \mathrm{~B}\end{array}$ & $\begin{array}{l}\boldsymbol{j}_{4} \\
0\end{array}$ & $i_{1}$ & $\begin{array}{c}\boldsymbol{j}_{1} \\
0\end{array}$ & $\begin{array}{l}\boldsymbol{j}_{2} \\
2 \mathrm{~V}\end{array}$ & $\begin{array}{c}\boldsymbol{j}_{3} \\
0\end{array}$ & $j_{1 \mathrm{~B}}$ & $i_{1}$ & $\begin{array}{c}\boldsymbol{j}_{\mathbf{1}} \\
0\end{array}$ & $\begin{array}{c}\boldsymbol{j}_{2} \\
0\end{array}$ & $\begin{array}{l}\boldsymbol{j}_{3} \\
1 \mathrm{~B}\end{array}$ & $j_{4}$ \\
\hline$i_{2}$ & 0 & $2 \mathrm{~V}$ & 0 & 0 & $i_{2}$ & $2 \mathrm{~V}$ & 0 & 0 & 0 & $\begin{array}{l}t_{1} \\
i_{2}\end{array}$ & $2 \mathrm{~V}$ & 0 & 0 & 0 \\
\hline$i_{3}$ & $1 \mathrm{~B}$ & $1 \mathrm{~B}$ & $2 \mathrm{~V}$ & $1 \mathrm{~B}$ & $i_{3}$ & $1 \mathrm{~B}$ & $1 \mathrm{~B}$ & $2 \mathrm{~V}$ & 1B & $i_{3}$ & $1 \mathrm{~B}$ & 1B & $2 \mathrm{~V}$ & 1B \\
\hline$i_{4}$ & 1V & 0 & 0 & 0 & $i_{4}$ & 0 & 0 & $1 \mathrm{~B}$ & 0 & $i_{4}$ & 0 & 0 & $1 \mathrm{~B}$ & 0 \\
\hline$i_{5}$ & 1V & 0 & 0 & $1 \mathrm{~B}$ & $i_{5}$ & $2 \mathrm{~V}$ & 0 & 0 & $2 \mathrm{~V}$ & $i_{5}$ & 0 & 0 & $2 \mathrm{~V}$ & $1 \mathrm{~B}$ \\
\hline$i_{6}$ & $2 \mathrm{~B}$ & 0 & $4 \mathrm{~B}$ & $\begin{array}{l}2 \mathrm{~B} \\
1 \mathrm{~V}\end{array}$ & $i_{6}$ & 3B & 0 & $1 \mathrm{~B}$ & $\begin{array}{l}4 \mathrm{~B} \\
1 \mathrm{~V}\end{array}$ & $i_{6}$ & $2 B$ & 0 & $4 \mathrm{~B}$ & $\begin{array}{l}1 \mathrm{~B} \\
1 \mathrm{~V}\end{array}$ \\
\hline \multicolumn{5}{|c|}{ Number of Vehicle Trips } & \multicolumn{5}{|c|}{ Number of Vehicle Trips } & \multicolumn{5}{|c|}{ Number of Vehicle Trips } \\
\hline$i_{1}$ & $\begin{array}{r}\boldsymbol{j}_{1} \\
0\end{array}$ & $\begin{array}{l}\boldsymbol{j}_{2} \\
10\end{array}$ & $\begin{array}{r}\boldsymbol{j}_{3} \\
2\end{array}$ & $\begin{array}{l}\boldsymbol{j}_{4} \\
0\end{array}$ & $i_{1}$ & $\begin{array}{c}\boldsymbol{j}_{1} \\
0\end{array}$ & $\begin{array}{l}\boldsymbol{j}_{2} \\
10\end{array}$ & $\begin{array}{r}\boldsymbol{j}_{3} \\
0\end{array}$ & $\boldsymbol{j}_{4}$ & $i_{1}$ & $\begin{array}{c}j_{1} \\
0\end{array}$ & $\begin{array}{c}\boldsymbol{j}_{2} \\
0\end{array}$ & $\begin{array}{c}\boldsymbol{j}_{3} \\
3\end{array}$ & $\begin{array}{r}\boldsymbol{j}_{4} \\
2\end{array}$ \\
\hline$i_{2}$ & 0 & 4 & 0 & 0 & $i_{2}$ & 2 & 0 & 0 & 0 & $i_{2}$ & 4 & 0 & 0 & 0 \\
\hline$i_{3}$ & 3 & 3 & 10 & 3 & $i_{3}$ & 3 & 3 & 10 & 3 & $i_{3}$ & 3 & 3 & 10 & 3 \\
\hline$i_{4}$ & 10 & 0 & 0 & 0 & $i_{4}$ & 0 & 0 & 3 & 0 & $i_{4}$ & 0 & 0 & 3 & 0 \\
\hline$i_{5}$ & 6 & 0 & 0 & 1 & $i_{5}$ & 10 & 0 & 0 & 4 & $i_{5}$ & 0 & 0 & 6 & 2 \\
\hline$i_{6}$ & 2 & 0 & 4 & $\begin{array}{l}2 \mathrm{~B} \\
5 \mathrm{~V}\end{array}$ & $i_{6}$ & 3 & 0 & 1 & $\begin{array}{l}1 \mathrm{~B} \\
10 \mathrm{~V}\end{array}$ & $i_{6}$ & 2 & 0 & 4 & $\begin{array}{l}1 \mathrm{~B} \\
3 \mathrm{~V}\end{array}$ \\
\hline
\end{tabular}

Table 4 - Optimal Assignment of Rescue Vehicles and Number of Trips (V=Van, B = Bus)

Finally, due to limitation in number of available resources and route disruptions, combination of 4 buses and 1 van are assigned to evacuate the remaining 100 evacuees to Yea $\left(j_{4}\right)$. In the same way for Eildon at the scenario $\mathrm{C}$ and due to severe road disruptions and longer traversal times to reach the accessible shelters, the optimal vehicle assignment is to transfer population by 6 buses and 1 van towards the defined shelters.

Slightly further, Thornton ( $i_{5}$ ) evacuees must be evacuated within 75 minutes to the safest and closest shelters. In the scenario A, this process is planned to be fulfilled by designation of one van trips 6 times transferring 52 evacuees to shelter $\left(\mathrm{j}_{1}\right)$ plus 1 bus transferring 69 people to shelter $\left(\mathrm{j}_{4}\right)$ trips 2 times.

While in the scenario B, the optimal vehicles assignment is to consider 2 vans travel 10 times between $i_{5}$ and $j_{1}$ and 2 vans travel 4 times between $i_{5}$ and $j_{4}$. Interestingly, in the scenario $C$, all the evacuees are evacuated to shelter $j_{3}$ and $j_{4}$ by the application of 2 vans travel 6 times and 1 bus travels 2 times to optimise the number of the utilised vehicles within the limited time windows. The results indicate that Mainton evacuees have more time and are evacuated by assigning fewer vehicles that travel more. Figure 6 illustrates a better representation for the optimal emergency evacuation vehicle assignment and number of trips in each scenario. 

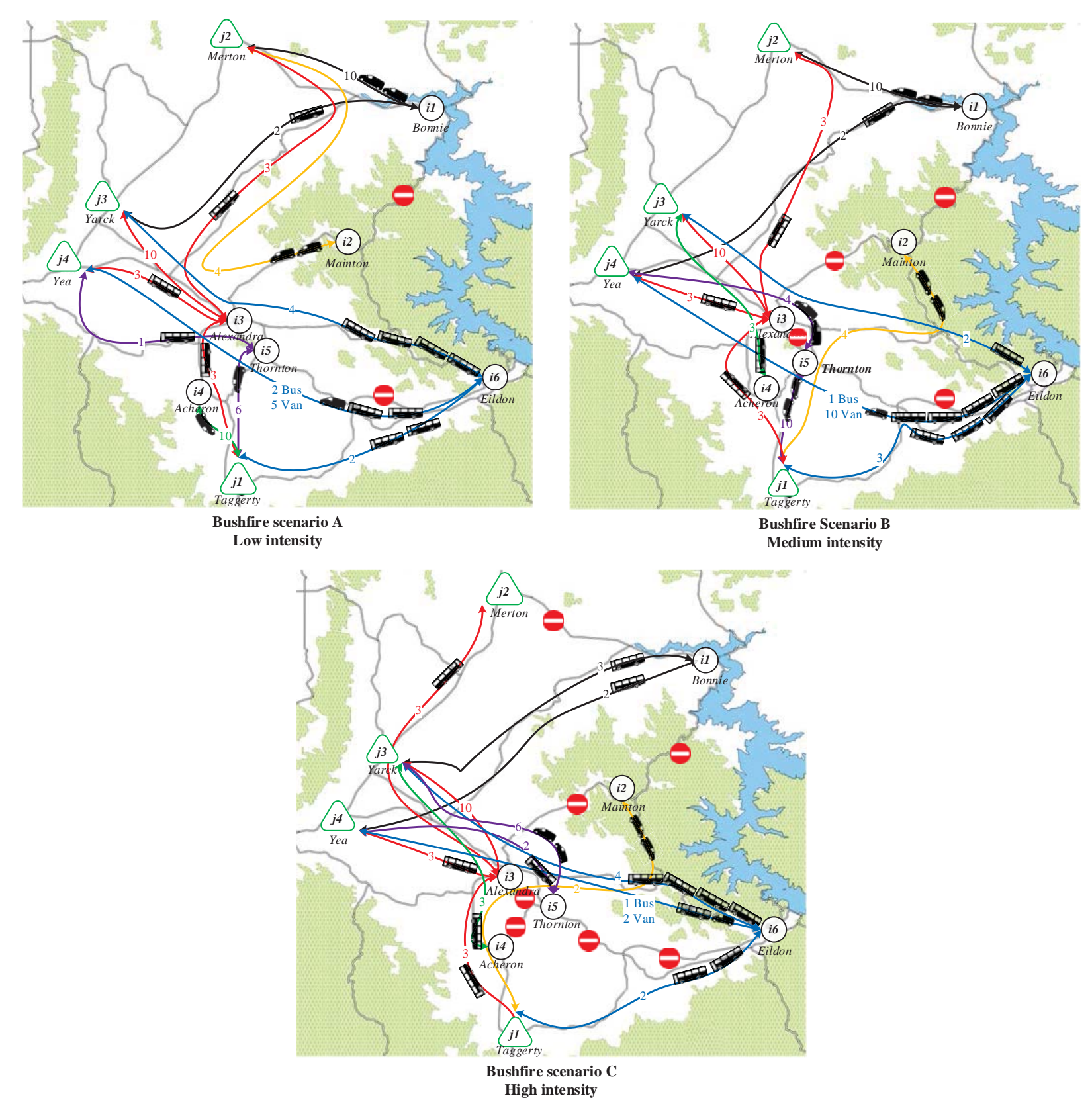

Figure 5 - Number of Vehicles and Trips for Evacuation

\subsection{Objective Function (Number of evacuated people)}

As the results show (Table 5), based on predefined bushfire scenarios, all the evacuees could safely be transferred to the safe shelters. Solving the model in the first step, results 88.8 for the objective function in scenario A. In scenario B, the first objective function value equals to 91.7 while due to bushfire conditions, the objective function value in scenario C is increased to 95.8. The increase in the preliminary objective values is caused by decreasing the transportation network size aftermath of bushfire propagation. In all the scenarios, however, the final objective value is 1036 and indicates that all the 1036 late evacuees in hazardous townships are safely routed and sheltered by optimal assignment of the available resources.

\subsection{Number of Required Vehicles}

The results of the first step solution of 'scenario A' indicates that minimum 13 buses and 10 vans are required to transfer the entire evacuee' population. However, the proposed figures are not necessarily optimal. Hence, in the second step and by the application of the $\varepsilon$-constraint method, the number of required vans is decreased to 9 vans to optimise the number of available 
resources. In the same way in scenario $\mathrm{B}$ and $\mathrm{C}$, the total numbers of assigned vehicles are optimised. For example, the total optimal number of required buses in 'scenario B' is 13 buses while there is an increase in number of vans to mitigate the impact of extra road disruptions and cover the evacuation demands. Accordingly, in scenario C, more vehicles are assigned to speed up the evacuation process.

Despite Eildon ( $\mathrm{i}_{6}$ ) is ranked as the second township in terms of the number of evacuees, the highest number of the vehicles in all scenarios are assigned to Eildon ( $\left.i_{6}\right)$ to evacuate people regarding to its short time window and long distance to nearest accessible shelters. Therefore, the model has assigned more vehicles to accelerate the evacuation process in Eildon.

\begin{tabular}{|c|c|c|c|}
\hline & $\begin{array}{c}\text { Bushfire Scenario } \\
\text { A } \\
\end{array}$ & $\begin{array}{c}\text { Bushfire Scenario } \\
\text { B } \\
\end{array}$ & $\begin{array}{c}\text { Bushfire Scenario } \\
\text { C }\end{array}$ \\
\hline First Step Objective Value & 88.8 & 91.7 & 95.8 \\
\hline First Step $\mathrm{TV}_{\mathrm{k}}$ & 13 Bus, 10 Van & 14 Bus, 10 Van & 15 Bus, 12 Van \\
\hline $\begin{array}{l}\text { Optimum Objective Value (Evacuated } \\
\text { People) }\end{array}$ & 1036 & 1036 & 1036 \\
\hline $\begin{array}{l}\text { Uncovered People } \\
\text { TV }_{k} \text { Optimum Number of Required Vehicles }\end{array}$ & $\begin{array}{c}0 \\
13 \text { Bus, } 9 \text { Van }\end{array}$ & $\begin{array}{c}0 \\
13 \text { Bus, } 11 \text { Van }\end{array}$ & $\begin{array}{c}0 \\
14 \text { Bus, 7 Van }\end{array}$ \\
\hline
\end{tabular}

Table 5 - Objective Functions Results

\subsection{Number of Required Shelters}

Figure 6 provides the results of sensitivity analyses. Results indicate that due to predetermined evacuation time windows, road blockages, distances and capacities, at least 4 shelters are required to be assigned to evacuate all evacuees in all the scenarios. Obviously, assigning more shelters increases the total objective function value.

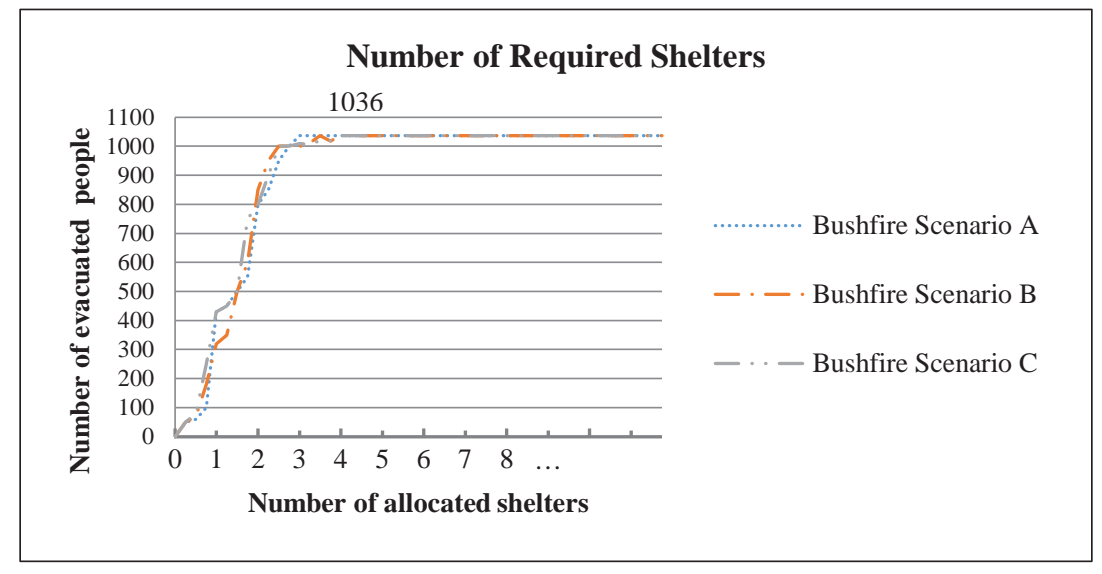

Figure 6 - Number of Required Shelters

Figure 7 depicts the percentage of usage capacity of the designated shelters for each scenario. In scenario $\mathrm{A}$, due to the close distance to the townships, most evacuees are sheltered at Taggerty $\left(\mathrm{j}_{1}\right)$. However, considering the increase in number of road disruptions in scenario B, the usage percentage of this shelter has decreased to $49.43 \%$ and evacuees are transferred to other shelters. Finally, in the scenario $\mathrm{C}$, most evacuees are evacuated to Yarck $\left(\mathrm{j}_{3}\right)$. The capacity usage of other shelters is shown in Figure 7. 


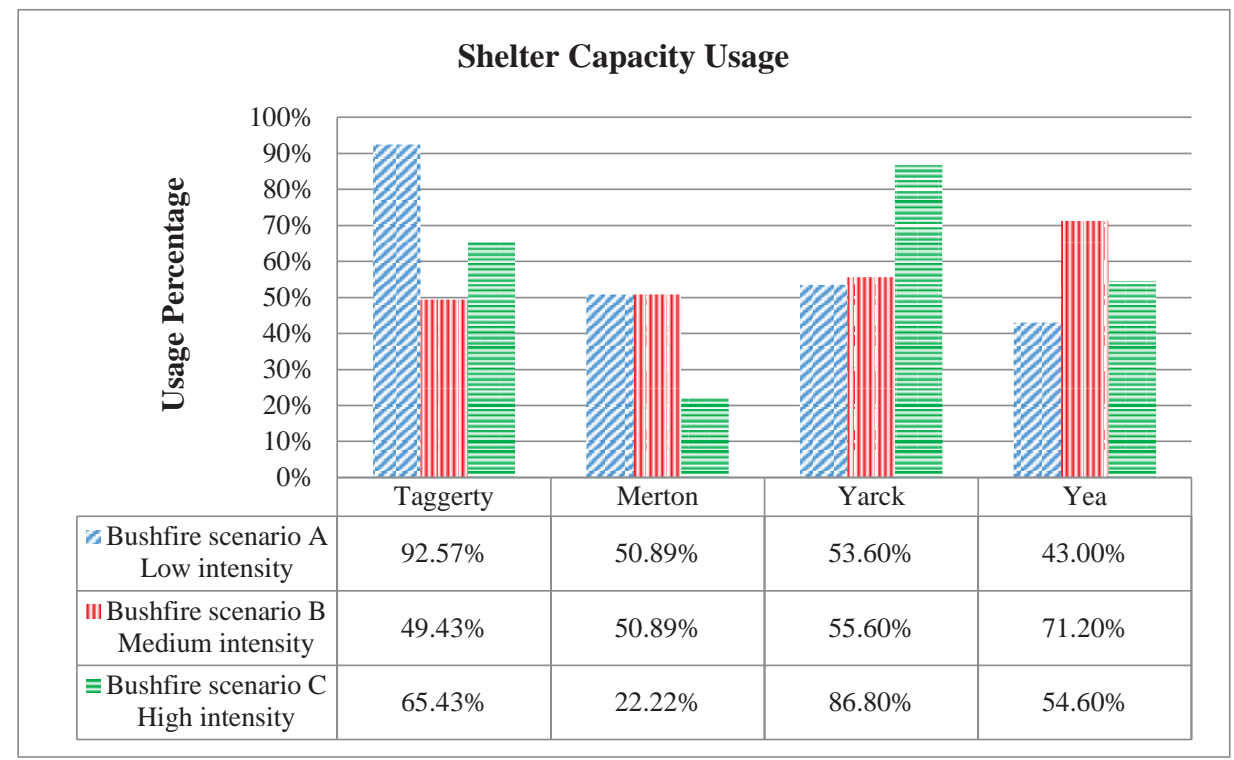

Figure 7- Shelters Capacity Usage

\subsection{Distribution of evacuees to assigned shelters}

In the scenario A, people are relocated to the assigned shelters normally, however, due to distance, limited time windows of assembly points and the Northern-Mainton road disruption, most evacuees (31\%) are evacuated to Taggerty $\left(\mathrm{j}_{1}\right)$. In the scenario B, Goulburn Valley highway disruption has impacted the transportation distribution and 353 people (34\%) are planned to be transferred to Yea $\left(\mathrm{j}_{4}\right)$ to maximise evacuated people in evacuation process (Figure 8).

Finally in scenario C, severe bushfire conditions have heavily disrupted the transportation network. Beside disruptions in the two arterial highways (Maroondah and Goulburn Valley), Taggerty-Thornton road as the only direct linkage to Taggerty $\left(\mathrm{j}_{1}\right)$ is disrupted. Consequently, most late evacuees $(42 \%)$ are evacuated to Yarck $\left(j_{3}\right)$ instead of Yea $\left(j_{4}\right)$. Nevertheless, regarding limited capacity of Yarck $\left(\mathrm{j}_{3}\right)$ rest of the evacuees was planned to be transported to the closest available shelters such as Yea $\left(\mathrm{j}_{4}\right)$ and Taggerty $\left(\mathrm{j}_{1}\right)$. Due to Maroondah highway blockage and the shortage of time, only $10 \%$ of population could be evacuated to Merton $\left(\mathrm{j}_{2}\right)$.

Bushfier scenario A Low intensity

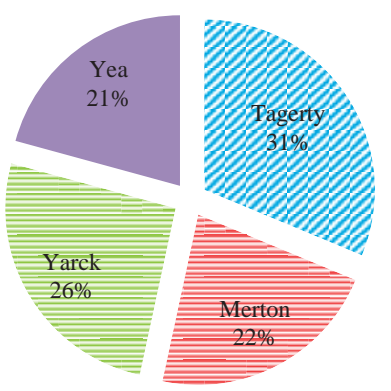

Bushfire scenario B Medium intensity

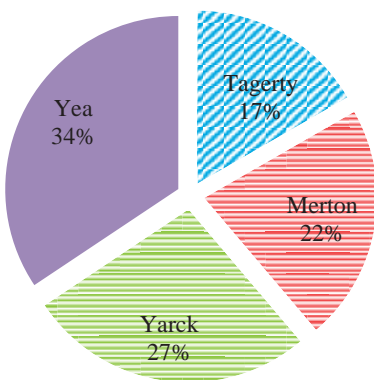

Bushfire scenario C high intensity

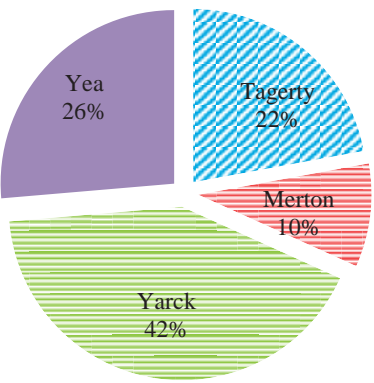

Figure 8 - Distribution of Evacuees to the Assigned Shelters

\section{Conclusion}

This paper developed a novel optimisation model to enhance the capacity of the emergency agencies to response to a bushfire. The model incorporated the key parameters and 
assumptions to adjust the potential impact of a range of constraints such as time window, road disruption and resource capacity. Using a real case study in Victoria, this model has dynamically optimised emergency evacuation routines including evacuation of late evacuees, dynamic selection of routing and, vehicle assignment and shelter allocation. Timely evacuation, distance to the nearest accessible shelters, and the number and capacity of required rescue vehicles are the key decision criteria to formulate the problem. The problem is formulated as a mixed-integer multi-objective linear programming model, which maximises the number of evacuees from towns at a higher risk to safe shelters by minimising available shelters and vehicles. The $\varepsilon$-constraint method is applied using a three-step solution framework to solve the model. The solution method firstly prioritised the objective functions and then converted the main model to two sub-models to hierarchically optimise the objective functions. Using three bushfire scenarios, the model optimises the number transferred evacuees, vehicle utilisation, shelter allocation and optimal routing. These scenarios include different wind directions influence bushfire propagation direction, speed and intensity to disrupt egress links.

The results show that all late evacuees (a total of 1036) can be evacuated within the time window assigned to different townships and available resources. However, a minimum of four operating shelters are needed at all times to absorb the late evacuees in the area. With three shelters, 91 out of 1,036 people could not be evacuated. Five shelters, on the other hand, will add an additional capacity but will require additional financial resources whilst remaining underutilised. In all the scenarios, Yarck plays a key role in providing refuge to evacuees because of its centrality to serve the region.

It is worth nothing that beside the evacuee's protective decisions, evacuation time limitations and available resources, there are other factors that may affect the evacuation process. Among them, bushfire propagation risks, multiple roads and traffic congestions are most critical ones, which need to be considered in future research.

\section{REFERENCES}

Alexander, D. E. 2000. "Confronting Catastrophe: New Perspectives on Natural Disasters,").

Arnol, C. 2007. "Firefighting Operations on the Urban Interface. Fellowship Report 20081," The Winston Churchill Memorial Trust of Australia).

Butry, D. T., Mercer, E., Prestemon, J. P., Pye, J. M., and Holmes, T. P. 2001. "What Is the Price of Catastrophic Wildfire?," J ournal of Forestry (99:11), pp. 9-17.

Cameron, P. A., Mitra, B., Fitzgerald, M., Scheinkestel, C. D., Stripp, A., Batey, C., Niggemeyer, L., Truesdale, M., Holman, P., and Mehra, R. 2009. "Black Saturday: The Immediate Impact of the February 2009 Bushfires in Victoria, Australia," Med J Aust (191:1), pp. 1116.

CFA Definitions. 2012. "Definitions." 2013, from http://www.cfa.vic.gov.au/warningsrestrictions/ fire-definitions/

Chan, C. P. 2010. "Large Scale Evacuation of Carless People During Short-and Long-Notice Emergency,").

Church, R. L., and Cova, T. J . 2000. "Mapping Evacuation Risk on Transportation Networks Using a Spatial Optimization Model," Transportation Research Part C: Emerging Technologies (8:1-6), pp. 321-336.

Cohon, J . L. 2004. Multiobjective Programming and Planning. DoverPublications.

Cova, T. J ., Dennison, P. E., and Drews, F. A. 2011. "Modeling Evacuate Versus Shelter-in-Place Decisions in Wildfires," Sustainability (3:10), pp. 1662-1687.

Ehrgott, M. 2006. "A Discussion of Scalarization Techniques for Multiple Objective Integer Programming," Annals of Operations Research (147:1), pp. 343-360. 
Ellis, S., Kanowski, P., and Whelan, R. 2004. National Inquiry on Bushfire Mitigation and Management.

He, S., Zhang, L., Song, R., Wen, Y., and Wu, D. 2009. "Optimal Transit Routing Problem for Emergency Evacuations," Transportation Research Board 88th Annual Meeting.

Kharuk, V., Kasischke, E., and Yakubailik, O. 2007. "The Spatial and Temporal Distribution of Fires on Sakhalin Island, Russia," International J ournal of Wildland Fire (16:5), pp. 556-562.

Li, A. C. Y., Nozick, L., Xu, N., and Davidson, R. 2012. "Shelter Location and Transportation Planning under Hurricane Conditions," Transportation Research Part E: Logistics and Transportation Review (48:4), pp. 715-729.

Lindell, M. K. 1995. "Assessing Emergency Preparedness in Support of Hazardous Facility Risk Analyses: Application to Siting a Us Hazardous Waste Incinerator," J ournal of hazardous materials (40:3), pp. 297-319.

Lindell, M. K., and Perry, R. W. 2003. Communicating Environmental Risk in Multiethnic Communities. Sage Publications.

Margulis, L., Charosky, P., Fernandez, J., and Centeno, M. A. 2006. "Hurricane Evacuation Decision-Support Model for Bus Dispatch," Fourth LACCEI International Latin American and Caribbean Conference for Engineering and Technology (LACCET "2006), "Breaking Frontiers and Barriers in Engineering: Education, Research, and Practice, pp. 21-23.

Mastrogiannidou, C., Boile, M., Golias, M., Theofanis, S., and Ziliaskopoulos, A. 2009. "Using Transit to Evacuate Facilities in Urban Areas: A Micro-Simulation Based Integrated Tool," Transportation Research Record: J ournal of the Transportation Research Board (3439), pp. 1-15.

Negreiros, M., and Palhano, A. 2006. "The Capacitated Centred Clustering Problem," Computers \& operations research (33:6), pp. 1639-1663.

Paveglio, T., Carroll, M. S., and J akes, P.J . 2008. "Alternatives to Evacuation Protecting Public Safety During Wildland Fire," J ournal of Forestry (106:2), pp. 65-70.

Pel, A. J., Bliemer, M. C., and Hoogendoorn, S. P. 2012. "A Review on Travel Behaviour Modelling in Dynamic Traffic Simulation Models for Evacuations," Transportation (39:1), pp. 97-123.

Podur, J ., Martell, D. L., and Knight, K. 2002. "Statistical Quality Control Analysis of Forest Fire Activity in Canada," Canadian J ournal of Forest Research (32:2), pp. 195-205.

Sayyady, F. 2007. "Optimizing the Use of Public Transit System in No-Notice Evacuations in Urban Areas." Mississippi State University.

Shahparvari, S., Chhetri, P., Abareshi, A., and Abbasi, B. 2015a. "Enhancement of Short-Notice Emergency Evacuation Response During Bushfire: A Multi-Objective EpsilonConstraint Optimisation Approach," International Symposium on Logistics Bologna, Italy: ISL pp. 10-17.

Shahparvari, S., Chhetri, P., Abareshi, A., and Abbasi, B. 2015b. "Enhancing Late Evacuation Emergency Response in Bushfire-Prone Areas: A Multi-Objective Optimization Approach," Transportation Research Board Washington D.C, USA: TRB.

Southworth, F. 1991. "Regional Evacuation Modeling: A State-of-the-Art Review".

Stepanov, A., and Smith, J . M. 2009. "Multi-Objective Evacuation Routing in Transportation Networks," European J ournal of Operational Research (198:2), pp. 435-446.

Teague, B., McLeod, R., and Pascoe, S. 2009. "Victorian Bushfires Royal Commission Interim Report," Parliament of Victoria, Melbourne). 
Victorian Bushfires Royal Commission Report. 2009. J uly 2009. Interim Report, Section (7).

Vira, C., and Haimes, Y. Y. 1983. Multiobjective Decision Making: Theory and Methodology. North-Holland.

Vuchic, V. R. 2005. Urban Transit: Operations, Planning, and Economics.

Westerling, A. L., Hidalgo, H. G., Cayan, D. R., and Swetnam, T. W. 2006. "Warming and Earlier Spring Increase Western Us Forest Wildfire Activity," Science (313:5789), pp. 940-943.

Whittaker, J., McLennan, J ., Elliott, G., Gilbert, J ., Handmer, J ., Haynes, K., and Cowlishaw, S. 2009. "Victorian 2009 Bushfire Research Response: Final Report," Bushfire CRC Post-fire Research Program in Human Behaviour. Bushfire CRC: Melbourne Available at http:// www.bushfirecrc.com/managed/resource.

Zelinsky, W., and Kosiński, L. A. 1991. The Emergency Evacuation of Cities: A Cross-National Historical and Geographical Study. Rowman \&Littlefield Publishers.

Zitzler, E., and Thiele, L. 1998. "Multiobjective Optimization Using Evolutionary Algorithms— a Comparative Case Study," Parallel problem solving from nature-PPSN V: Springer, pp. 292-301.

Copyright: (C) 2015 Shahparvari, Chhetri, Abareshi, Abbasi \&Alahakoon. This is an openaccess article distributed under the terms of the Creative Commons Attribution-

NonCommercial 3.0 Australia License, which permits non-commercial use, distribution, and reproduction in any medium, provided the original author and AJ IS are credited.

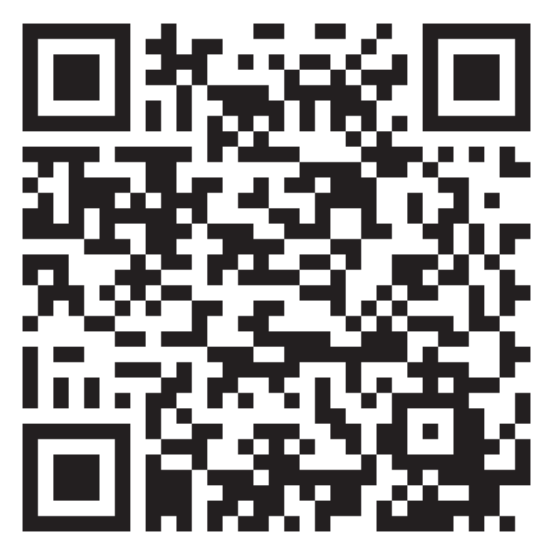

